\title{
Hydrogen Treatment Protects Mice Against Chronic Pancreatitis by Restoring Regulatory T Cells Loss
}

\author{
Luguang Chen ${ }^{\mathrm{a}}$ Chao Ma ${ }^{\mathrm{a}}$ Yun Bian ${ }^{\mathrm{a}}$ Jing Li ${ }^{\mathrm{a}}$ Tiegong Wang ${ }^{\mathrm{a}} \mathrm{Li} \mathrm{Su}^{\mathrm{b}}$ \\ Jianping $\mathrm{Lu}^{\mathrm{a}}$ \\ aDepartment of Radiology, Changhai Hospital of Shanghai, Second Military Medical University, \\ bSchool of Pharmacy, Second Military Medical University, Shanghai, China
}

\section{Key Words}

Pancreatitis • Hydrogen $•$ Immunoregulation • Treg

\begin{abstract}
Background/Aims: Chronic pancreatitis is an inflammatory disease of the pancreas characterized by progressive tissue destruction and fibrogenesis. The development of chronic pancreatitis is associated with immune cell dysregulation. Currently, the specific and effective treatment of chronic pancreatitis remains absent. Methods: By using an L-arginine induced chronic pancreatitis mouse model, we tested the therapeutic potential of hydrogen, a strong hydroxyl radicals scavenger, in the chronic pancreatitis model. Tissue inflammation, damage and fibrosis were analyzed on HE, TUNEL, MPO, and sirius staining. Pancreas levels of MDA content, SOD activity, TNF- $\alpha$, IL-10 cytokine expression and serum amylase and lipase activity were determined by ELISA and absorbance assay. Apoptosis, T cells subtype proportion and intracellular level of reactive oxygen species (ROS) were analyzed by flow cytometry. Tregs adoptive transfer and CD25 neutralization were used to validate the role of Tregs in chronic pancreatitis. Results: We found that hydrogen treatment significantly improved multiple symptoms of chronic pancreatitis. The number of Tregs was reduced in chronic pancreatitis mice, while hydrogen treatment restored the Treg loss by L-arginine administrations. Depletion of Tregs abolished the protective effect of hydrogen treatment in chronic pancreatitis. In vitro study showed that hydrogen blocked ROS generation in Tregs and promoted Tregs survival. Conclusion: Hydrogen treatment showed reliable benefits in controlling the severity of chronic pancreatitis. Our study supported that hydrogen could be used as a novel treatment in chronic pancreatitis patient in the future.

(C) 2017 The Author(s)

Published by S. Karger AG, Basel
\end{abstract}

\section{Introduction}

Chronic pancreatitis is characterized by sustained inflammation in the pancreas, which leads to the irreversible change of the normal structure and function of normal pancreas.

Jianping $L u, M D, P h D$ and Li Su, PhD
Department of Radiology, Changhai Hospital, Second Military Medical University

No.168 Changhai Road, Shanghai 200433 (China)

Tel. +86 021 31162146; E-Mail cjr.lujianping@vip.163.com 
Prominent fibrosis is a major histological feature of chronic pancreatitis [1]. Chronic pancreatitis results from both environmental (such as alcohol abuse) and genetic factors (such as mutation in a trypsin-controlling gene) [2]. Pancreatic fibrogenesis is a typical response to repeatedly acinar injury. This process involves a complex of orchestration of cytokines, chemokines and growth factors derived from immune cells and other cells. Although the exact mechanisms for the pathogenesis of chronic pancreatitis are not completely understood, the role of dysregulation of immune cells has attracted extensive attentions $[3,4]$. Inhibition of inflammatory response by drug treatment or inflammatory cell ablation has been confirmed effective in treating pancreatitis [5, 6].

$\mathrm{T}$ cells play a central role in the adaptive immune response. The role of $\mathrm{T}$ cells in the development of both acute and chronic pancreatitis has been well documented [4, 7]. T cells, especially $\mathrm{CD} 4^{+} \mathrm{T}$ cells contributed to the progress of acute pancreatitis, evidenced by depletion of $\mathrm{CD}^{+} \mathrm{T}$ cells but not $\mathrm{CD}^{+} \mathrm{T}$ cells significantly reduced the severity of acute pancreatitis [8]. In chronic pancreatitis, significant increase in $\mathrm{CD}^{+}$and $\mathrm{CD} 8^{+} \mathrm{T}$-cell infiltration was observed in pancreas of patients with chronic pancreatitis [9]. Moreover, strong IL-10 based $\mathrm{T}$ cell response against pancreatitis-associated antigen was found in chronic pancreatitis patients [10]. Further study confirmed that pancreatitis-specific IL-10 responses were mediated by IL- $10^{+}$IFN $-\gamma^{-}$FoxP $3^{+}$regulatory T cells (Tregs). The expansion of these Tregs helped to suppress conventional $\mathrm{T}$ cell response in chronic pancreatitis patients [10].

Hydrogen gas $\left(\mathrm{H}_{2}\right)$, a well-known molecule with the simplest structure, has been demonstrated recently to have selectively reduced reactive oxygen species (ROS) and antiinflammatory properties $[11,12]$. Instead of $\mathrm{H}_{2}$, hydrogen-rich saline, which is safer and easier for administration, may be more suitable for clinical applications. Beneficial effects of molecular hydrogen have been observed essentially in ischemia-reperfusion (I/R) injury [13, 14], type 2 diabetes [15], Alzheimer's disease, Parkinson's disease [16], acute pancreatitis [17], and other oxidative stress-related diseases. However, there are few researches to explore the protective mechanisms of hydrogen for chronic pancreatitis. As immune cells, especially $\mathrm{T}$ cell played critical role in the pathogenesis of chronic pancreatitis, whether hydrogen influenced immune cells remains elusive.

Here we used a well-established mouse model of chronic pancreatitis to evaluate the effects of hydrogen on chronic pancreatitis and explore the possible mechanisms involved. We will focus on the regulatory effects of hydrogen on immune cells in chronic pancreatitis.

\section{Materials and Methods}

\section{Animals and experiment design}

Male C57BL/6J mice (18-20 g) were supplied by the Animal Research Center at Second Military Medical University. All surgical procedures and care administered to the animals were approved by the institutional ethic committee, and this study also complied with the criteria in Guide for the Care and Use of Laboratory Animals.

45 mice were randomly assigned to 3 groups (each group had 15 mice): control, chronic pancreatitis, and chronic pancreatitis $+2 \%$ hydrogen. Chronic pancreatitis was induced by intraperitoneal injection of $10 \mathrm{mg} / \mathrm{kg}$ L-arginine (Sigma-Aldrich, St. Louis, MO, USA) for 28 days. The mice in the hydrogen group received 2\% hydrogen by Oxyhydrogen atomizing machine (Shanghai Asclepius Meditech Ltd, China) for 1 $\mathrm{h}$ after operation, respectively. At the indicated time points, the surviving mice in each group were randomly sacrificed, and blood and pancreatic samples were collected. Blood samples were centrifuged and then sera were collected and stored at $-20^{\circ} \mathrm{C}$. Pancreatic samples were stored at $-80^{\circ} \mathrm{C}$ for subsequent measurement.

Histological analysis

Pancreas from mice was fixed in 4\% paraformaldehyde, dehydrated for $12 \mathrm{~h}$, embedded in paraffin wax, cut into $3 \mu \mathrm{m}$-thick slices, and then examined via light microscopy (Olympus, Tokyo, Japan) for hematoxylineosin (HE), Sirius stain, TUNEL, and MPO immunohistochemistry, respectively. 


\section{Cellular Physiology Cell Physiol Biochem 2017;44:2005-2016 \begin{tabular}{l|l|l} 
and Biochemistry & DOI: 10.1159/000485906 & $\begin{array}{l}\text { (c) } 2017 \text { The Author(s). Published by S. Karger AG, Basel } \\
\text { www.karger.com/cpb }\end{array}$
\end{tabular} \\ Chen et al.: Hydrogen Protects Mice against Chronic Pancreatitis by Tregs}

ELISA

Cytokines in the medium was measured using ELISA kit (eBioscience, San Diego, CA). Levels of IL-10, TNF- $\alpha$ and TGF- $\beta$ were assessed by ELISA using monoclonal antibodies and the procedure recommended by the supplier.

\section{Measurement of superoxide dismutase (SOD) and malondialdehyde (MDA) in pancreas}

Measuring the activity of SOD and MDA in pancreas tissues has been described in previous report [18]. SOD activity as well as MDA contents of the pancreas were tested by chromatometry kit (Invitrogen, Camarillo, CA, USA) and enzymatic-spectrophotometric kit (Jian Cheng Biotech Ltd, China), respectively. The SOD activity value measurement was used to assess polymorphonuclear leukocyte infiltration, and the levels of MDA were interpreted as an indicator of lipid peroxidation.

\section{Amylase and lipase activity assay}

Amylase activity was measured by starch-iodine method. $10 \mu \mathrm{L} 1 \%$ starch solution (w/v) and $5 \mu \mathrm{L}$ sample were incubated at $37^{\circ} \mathrm{C}$ for $30 \mathrm{~min}$. After incubation, $\left.30 \mu \mathrm{L} \mathrm{HCl} \mathrm{(1} \mathrm{M)} \mathrm{was} \mathrm{added.} \mathrm{An} \mathrm{aliquot} \mathrm{(150} \mu \mathrm{L}\right)$ of iodine reagent ( $5 \mathrm{mM} \mathrm{I}_{2}$ and $5 \mathrm{mM} \mathrm{KI}$ ) was added and the reaction mixture was centrifuged at $12,000 \times \mathrm{g}$ for $1 \mathrm{~min}$. Absorbance at $600 \mathrm{~nm}$ of the reaction mixture was measured.

Lipase activity was measured using p-nitrophenylmyristate as substrate. $50 \mu \mathrm{L}$ ammonium bicarbonate solution (100 mM), $5 \mu \mathrm{L}$ sample, $100 \mu \mathrm{L} 1 \%$ Triton-X 100, and $8 \mu \mathrm{L}$ p-nitrophenylmyristate (10 mM) were incubated at room temperature for $15 \mathrm{~min}$. The reaction mixture was measured at $405 \mathrm{~nm}$ for absorbance changes.

\section{Flow cytometry analysis of $T$ cell subtype}

Analysis of T cell subtype was performed by flow cytometry (BD Biosciences, San Jose, CA). The cells were collected and stained with PE-CD3, FITC-CD4 and APC-CD8 (eBioscience), respectively, to detect the percentage of $\mathrm{CD}^{+}{ }^{+} \mathrm{T}, \mathrm{CD} 4{ }^{+} \mathrm{T}$, and CD8 ${ }^{+} \mathrm{T}$ cells. FITC-CD4, PE-Foxp3, and APC-CD25 were used to stain Treg.

\section{Treg culture and adoptive transfer experiments}

Treg cells were purified using MOUSE CD4 ${ }^{+} \mathrm{CD} 25^{+}$Regulatory T Cell Isolation Kit (Miltenyi Biotec, Germany) according to the manufacturers' instructions. Then Treg cells were cultured in complete medium (RPMI 1640 containing 10 \% FBS and 1 \% Pen/Strep all from Gibco, CA, USA). For adoptive transfer experiments, $1 \times 10^{6}$ cells cultured Treg cells were transferred into each recipient mouse via tail intravenous injection.

\section{Neutralization of CD25}

Anti-mouse CD25 functional grade purified was purchased from eBioscience. Rat IgG2b K (catalog 164031, eBioscience) was used as an isotype-matched control. In chronic pancreatitis model, male C57 mice were intraperitoneal injected with anti-CD25 (1 mg/kg) on day 1, 8, 15, and 22.

\section{Hydrogen-Rich saline Preparation}

Hydrogen-Rich saline was prepared by an equipment provided by the Department of Diving Medicine (Second Military Medical University) as previously described [19]. Hydrogen-Rich saline was freshly prepared every day to ensure that the hydrogen concentration of more than $1 \mathrm{mM}$ was maintained.

\section{Cell apoptosis assay}

The apoptotic cells were quantified using the annexin V and PI double staining kit (BD Biosciences). Briefly, cells were collected, washed with PBS, and resuspended in $200 \mu \mathrm{L}$ binding buffer containing $5 \mu \mathrm{L}$ annexin $\mathrm{V}(10 \mu \mathrm{g} / \mathrm{mL})$ and $10 \mu \mathrm{L}$ PI $(20 \mu \mathrm{g} / \mathrm{mL})$ for $30 \mathrm{~min}$. Then samples were immediately analyzed using flow cytometry.

\section{ROS production measurement}

ROS levels were detected using a flow cytometer and a microplate spectrophotometer (Molecular Devices, Sunnyvale, CA, USA). Cells were harvested and washed with PBS and suspended in $10 \mu \mathrm{M}$ $5(6)$-carboxy-2', $7^{\prime}$-dichlorodihydrofluorescein diacetate (carboxy- $\mathrm{H}_{2} \mathrm{DCFDA}$; Invitrogen) at $37{ }^{\circ} \mathrm{C}$ for 20 min. The cells were then washed twice with PBS and subjected to flow cytometry analysis. 


\section{Cellular Physiology Cell Physiol Biochem 2017;44:2005-2016 \begin{tabular}{l|l} 
and Biochemistry & DOI: 10.1159/000485906 2017 The Author(s). Published by S. Karger AG, Basel \\
www.karger.com/cpb
\end{tabular}

\section{Statistical analysis}

Results are expressed as mean \pm standard deviation (SD). The data were analyzed by one-way ANOVA analysis of variance followed by Dunnett's test. Statistical differences were considered statistically significant when $\mathrm{P}<0.05$.

\section{Results}

\section{Hydrogen treatment reduced chronic pancreatitis damage}

The daily L-arginine administration for 28 days produced evidence of chronic pancreatitis in Model group mice, including increased pancreas size/weight, water content of pancreas, abnormal architecture, increased TUNEL+ acinar cells, massive MPO+ neutrophil infiltration, elevated serum amylase/lipase levels and pancreatic fibrosis (Figs. 1A C, Figs. 2A B and Fig. 3C). Compared with Model group mice, daily treatment of $2 \%$ hydrogen significantly reduced the severity of chronic pancreatitis. $2 \%$ hydrogen inhibited the increase of pancreas weight and water content caused by L-arginine (Figs. 1A C and Fig. 3C). Also, pathological score, number of TUNEL+ acinar cells and neutrophil infiltration were greatly improved with $2 \%$ hydrogen treatment (Figs. 2A B). We also observed the lower serum amylase/lipase levels in $2 \%$ hydrogen treated mice compared with Model group (Fig. 3C). Importantly, pancreatic fibrosis was partly reversed by $2 \%$ hydrogen (Fig. $2 \mathrm{~A}$ ).

As oxidative stress and cytokine profile change played critical roles in the pathogenesis of pancreatitis [20,21], we checked pancreas SOD activity and MDA levels. As expected, reduced SOD activity and increased MDA levels were observed in Model group mice compared with Control group. 2\% hydrogen treatment restored decreased SOD activity and reduced MDA levels in pancreas which suggested $2 \%$ hydrogen significantly improved oxidative stress induced by L-arginine (Fig. 3A). In addition, $2 \%$ hydrogen blocked the increased pro-inflammatory cytokine TNF- $\alpha$ production but enhanced antiinflammatory cytokine IL-10 expression (Fig. 3B). This interesting finding led us to further investigate how hydrogen impact the immune cells in chronic pancreatitis model.

Treg cells were increased after hydrogen treatment in chronic pancreatitis mice

As the main source of cytokines, $\mathrm{T}$ cells, especially $\mathrm{CD}^{+} \mathrm{T}$ cells were reported to be critical in the development of pancreatitis $[8,10]$. We checked CD4 ${ }^{+}$ and $\mathrm{CD}^{+}$ratio in both peripheral blood mononuclear cells (PBMCs) and spleen mononuclear cells (MNCs). As shown in Figs. $4 \mathrm{~A}$ and $\mathrm{B}$, similar $\mathrm{CD}^{+} / \mathrm{CD}^{+}$ratios were observed in Control, Model and Model $+2 \%$ hydrogen groups. However, a significant decrease of percentage of $\mathrm{CD}^{2} 5^{+} \mathrm{Foxp}^{+}{ }^{+}$Tregs in both PBMCs and spleen MNCs were found in chronic pancreatitis Model group (Figs. 4C and D). Interestingly, the treatment of $2 \%$ hydrogen reversed the loss of $\mathrm{CD} 25^{+} \mathrm{Foxp} 3^{+}$Tregs

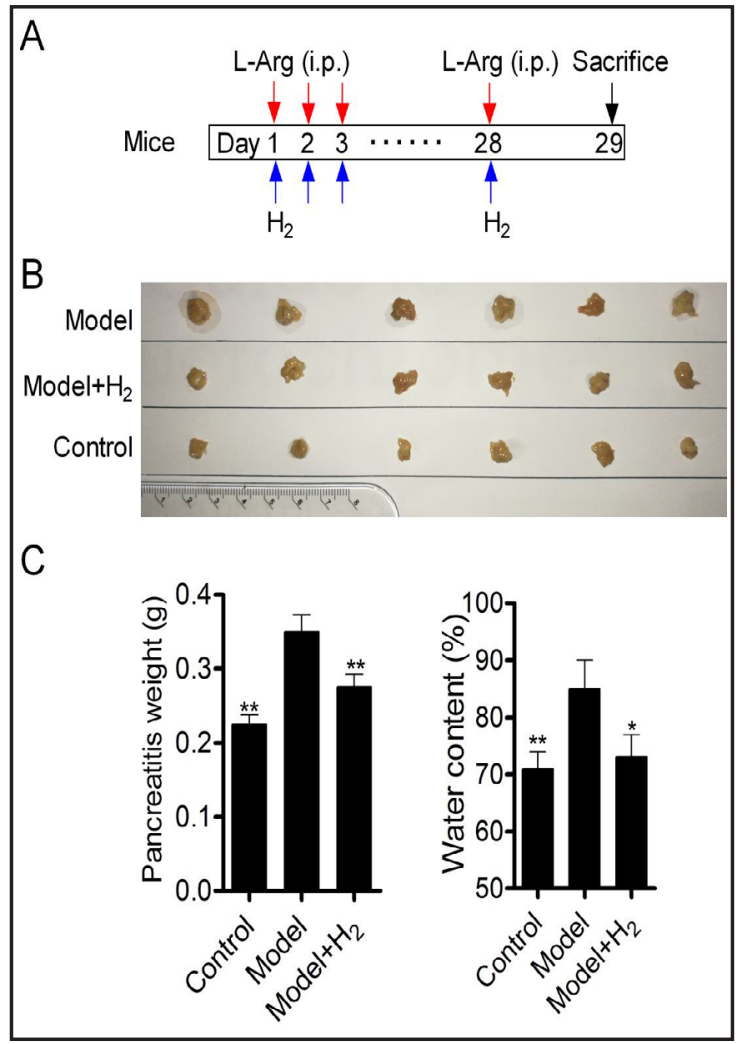

Fig. 1. Hydrogen mitigated edema in chronic pancreatitis mice. Time schedule (A), pancreas photographs (B), pancreas weight and water content (C) were designed and measured at $24 \mathrm{~h}$ after operation. ${ }^{*} \mathrm{P}<0.05$ and ${ }^{*} \mathrm{P}<0.01$ compared with model group. 
Fig. 2. Hydrogen protected against chronic pancreatitis in mice by histological examination. (A) Tissue inflammation, damage and fibrosis were analyzed on HE (magnification $\times 200$ ), TUNEL, MPO (magnification $\times 400$ ), and Sirius staining (magnification $\times 100$ ). (B) Quantification of (A) ${ }^{* *} \mathrm{P}<0.01$ compared with model group.
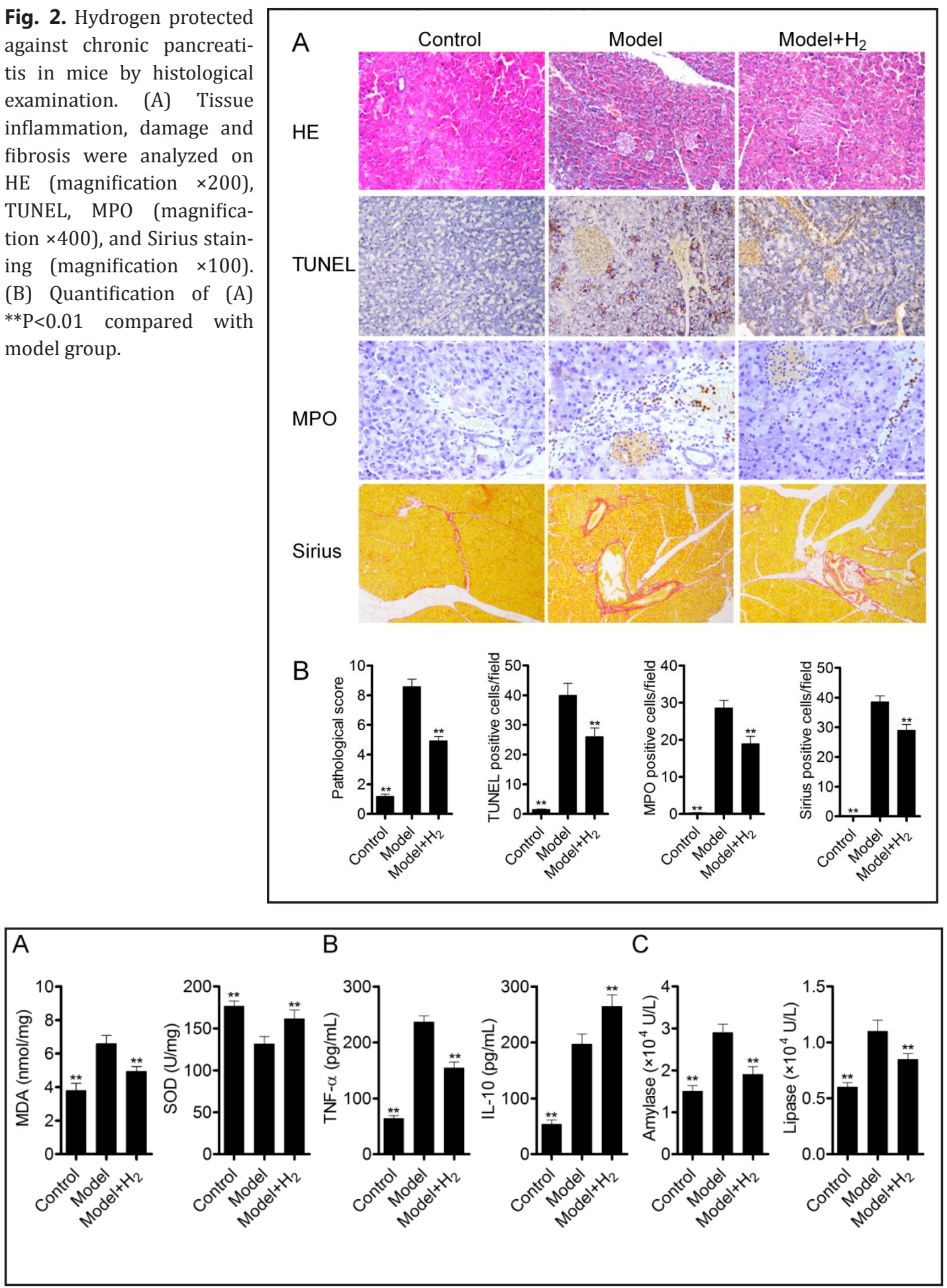

Fig. 3. Hydrogen inhibited oxidative stress, inflammatory cytokines, and the levels of amylase and lipase in chronic pancreatitis mice. Pancreas levels of MDA content, SOD activity (A), TNF- $\alpha$, IL-10 (B) cytokine expression and serum amylase and lipase activity (C) were determined by ELISA and absorbance assay. $* * \mathrm{P}<0.01$ compared with model group.

chronic pancreatitis (Figs. 4C and D). These data implied that Treg cells might be implicated in the development of chronic pancreatitis. 


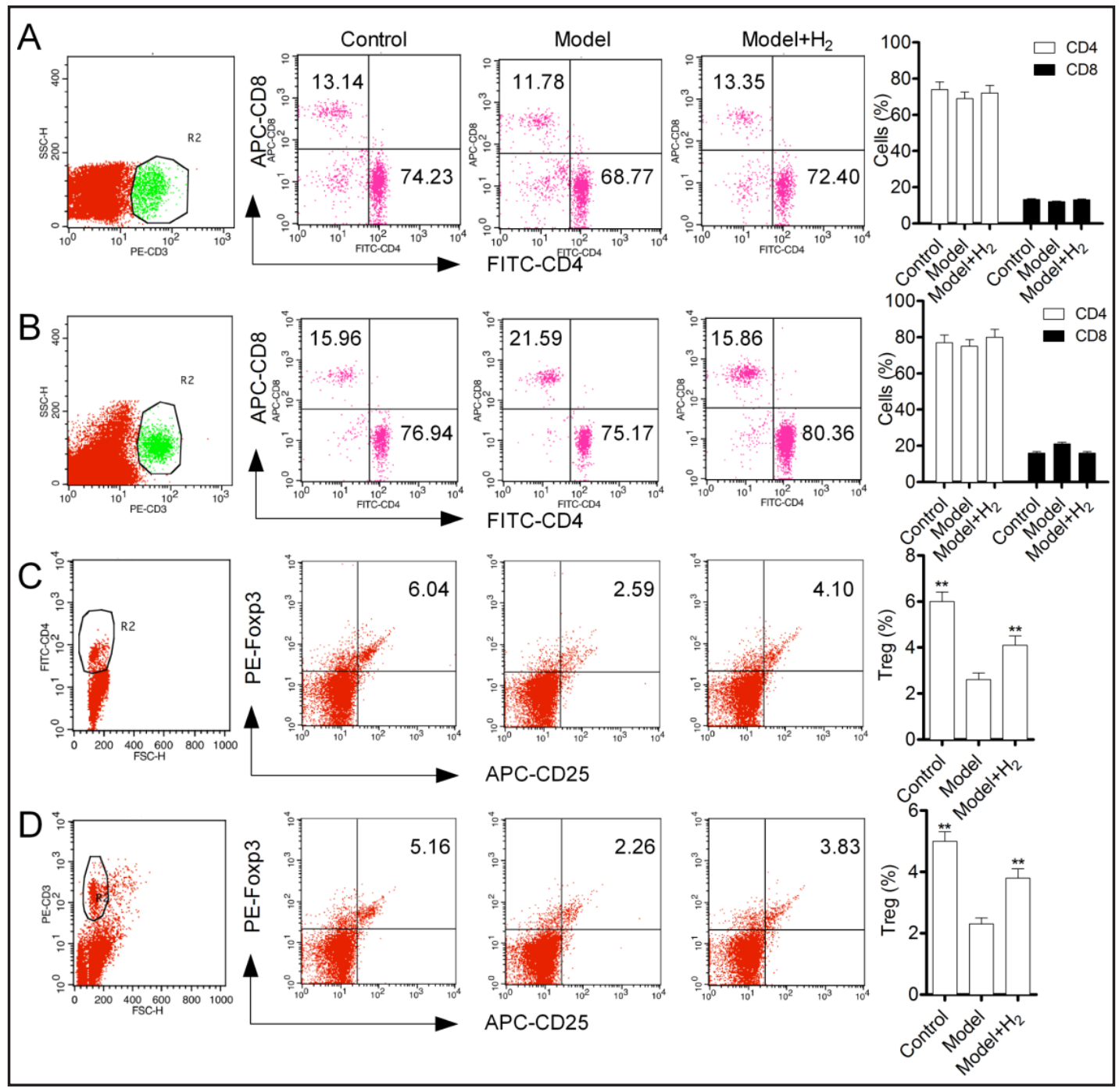

Fig. 4. Effects of hydrogen on the differentiation of spleen and peripheral blood T cell subtypes by flow cytometry. Cells were separated and incubated with different antibodies for $30 \mathrm{~min}$. The proportion of spleen CD4 and CD8 (A), Treg (C) and peripheral blood CD4 and CD8 (B), Treg (D) was analyzed by flow cytometry. ${ }^{* *} \mathrm{P}<0.01$ compared with model group.

The protective effect of hydrogen on chronic pancreatitis was mediated by Tregs

To validate the role of Tregs in chronic pancreatitis, purified Tregs were adoptively transferred into mice with chronic pancreatitis (Figs. 5A and B). Compared with Model group, mice received Tregs transfer showed significantly reduced pancreas size/weight and water content (Figs. 5C and D). Also, improved pathological score, number of TUNEL+ acinar cells, MPO+ neutrophil infiltration were found in Tregs transfered group (Figs. 6A and B). In addition, reduced serum amylase/lipase levels and pancreatic fibrosis were observed in Tregs group compared with Model group (Fig. 6A and 7C). Tregs transfer shown similar capability in reducing the severity of chronic pancreatitis with severity of chronic pancreatitis with $2 \%$ hydrogen treatment.

To verify whether the protective effect of $2 \%$ hydrogen treatment on chronic pancreatitis was mediated by elevated Tregs, we used mouse CD25 neutralizing antibody to deplete Tregs in $2 \%$ hydrogen treated chronic pancreatitis mice. As shown in Figs. $5 \mathrm{C}$ and D, depletion of Tregs almost completely abolished the protective effect of $2 \%$ hydrogen treatment

\section{KARGER}




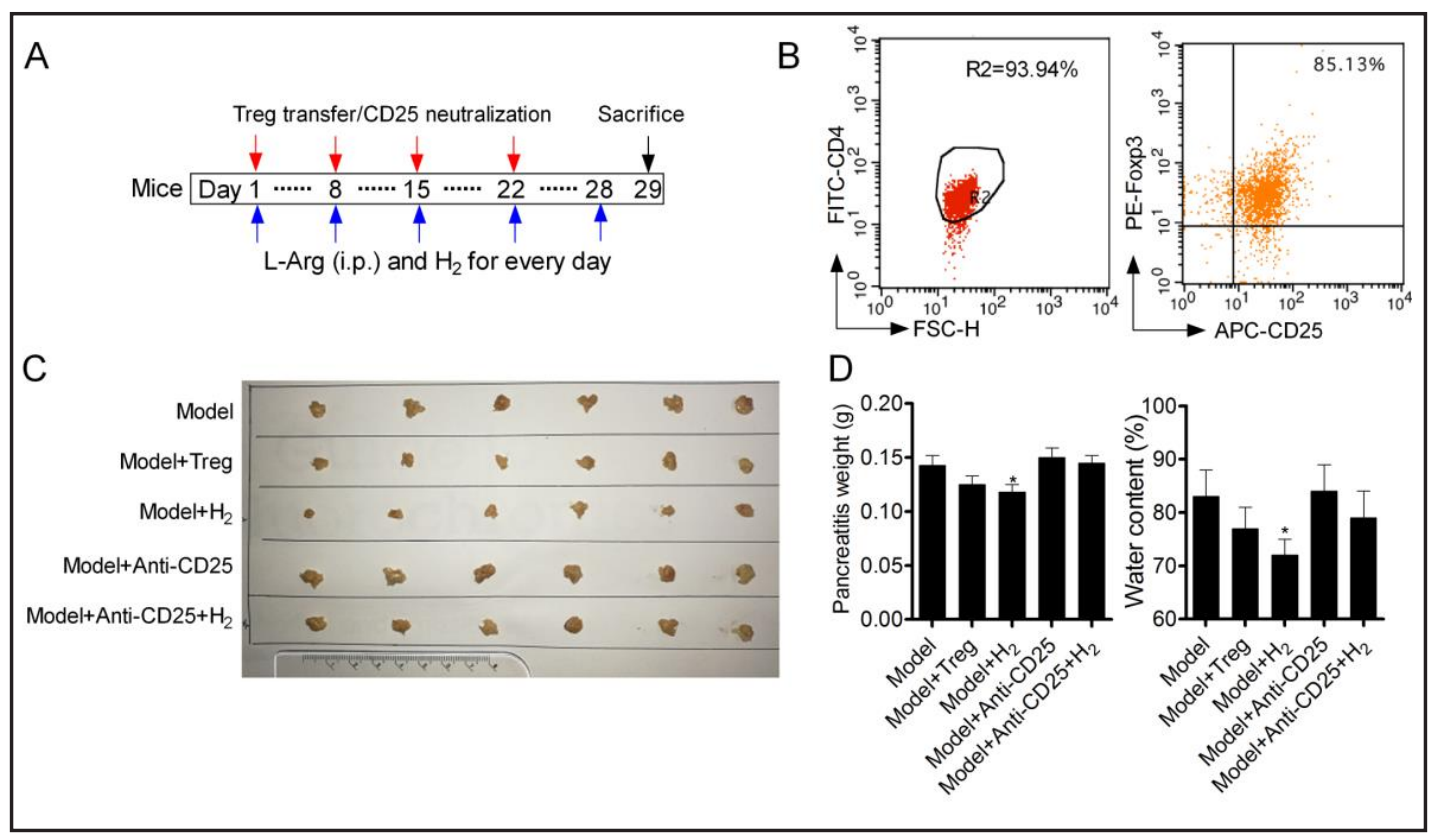

Fig. 5. Adoptive transfer of Treg cells ameliorated edema of chronic pancreatitis. Time schedule (A), purity of Treg (B) pancreas photographs (C), pancreas weight and water content (D) were designed and measured at $24 \mathrm{~h}$ after operation. ${ }^{*} \mathrm{P}<0.05$ compared with model group.

on chronic pancreatitis, evidenced by increased pancreas size/weight, water content of pancreas and deteriorated pancreas pathological score, increased TUNEL+ acinar cells and MPO+ neutrophil in pancreas (Figs. 5C and D, Figs. 6A and B). These data supported that the increased Tregs was responsible for the beneficial effect of $2 \%$ hydrogen treatment on chronic pancreatitis.

Moreover, we checked the oxidative stress and cytokine production on chronic pancreatitis mice with Tregs transfer, $2 \%$ hydrogen treatment and $2 \%$ hydrogen treatment with CD25 neutralizing antibody. Consistent with the results mentioned above, Tregs transfer reduced oxidative stress and TNF- $\alpha$ level but increased IL-10 production (Figs. 7A and B). In contrast, depletion of Tregs by CD25 neutralizing antibody abolished reduced oxidative stress and TNF- $\alpha$ level by $2 \%$ hydrogen treatment, also, increased IL-10 levels went back with Tregs depletion (Figs. 7A and B).

\section{Hydrogen-Rich saline inhibited $\mathrm{H}_{2} \mathrm{O}_{2}$ induced Treg apoptosis, quantity and ROS level}

We next explored the mechanism how hydrogen restored Treg loss in chronic pancreatitis. To mimic the oxidative stress environment in chronic pancreatitis mice, we treated Tregs with $\mathrm{H}_{2} \mathrm{O}_{2}$, which caused increased apoptosis of Tregs and reduced Treg percentage in spleen MNCs (Figs. 8A and B). Hydrogen-Rich saline prevented the apoptosis and restored Treg loss induced by $\mathrm{H}_{2} \mathrm{O}_{2}$ (Figs. $8 \mathrm{~A}$ and $\mathrm{B}$ ). The protective effects of hydrogen may be attributed to reduced ROS production by hydrogen (Fig. $8 \mathrm{C}$ ). In addition, we showed that hydrogen can also restore impaired production of anti-inflammatory cytokine IL-10 and TGF- $\beta$ caused by $\mathrm{H}_{2} \mathrm{O}_{2}$ (Fig. 8D).

\section{Discussion}

In our study, we found that $2 \%$ hydrogen treatment significantly protected mice from L-arginine induced chronic pancreatitis. The mechanism of the protective effect of hydrogen treatment could be explained by increased Tregs in hydrogen treated chronic pancreatitis mice. Tregs depletion by CD25 neutralizing antibody abolished the protective 


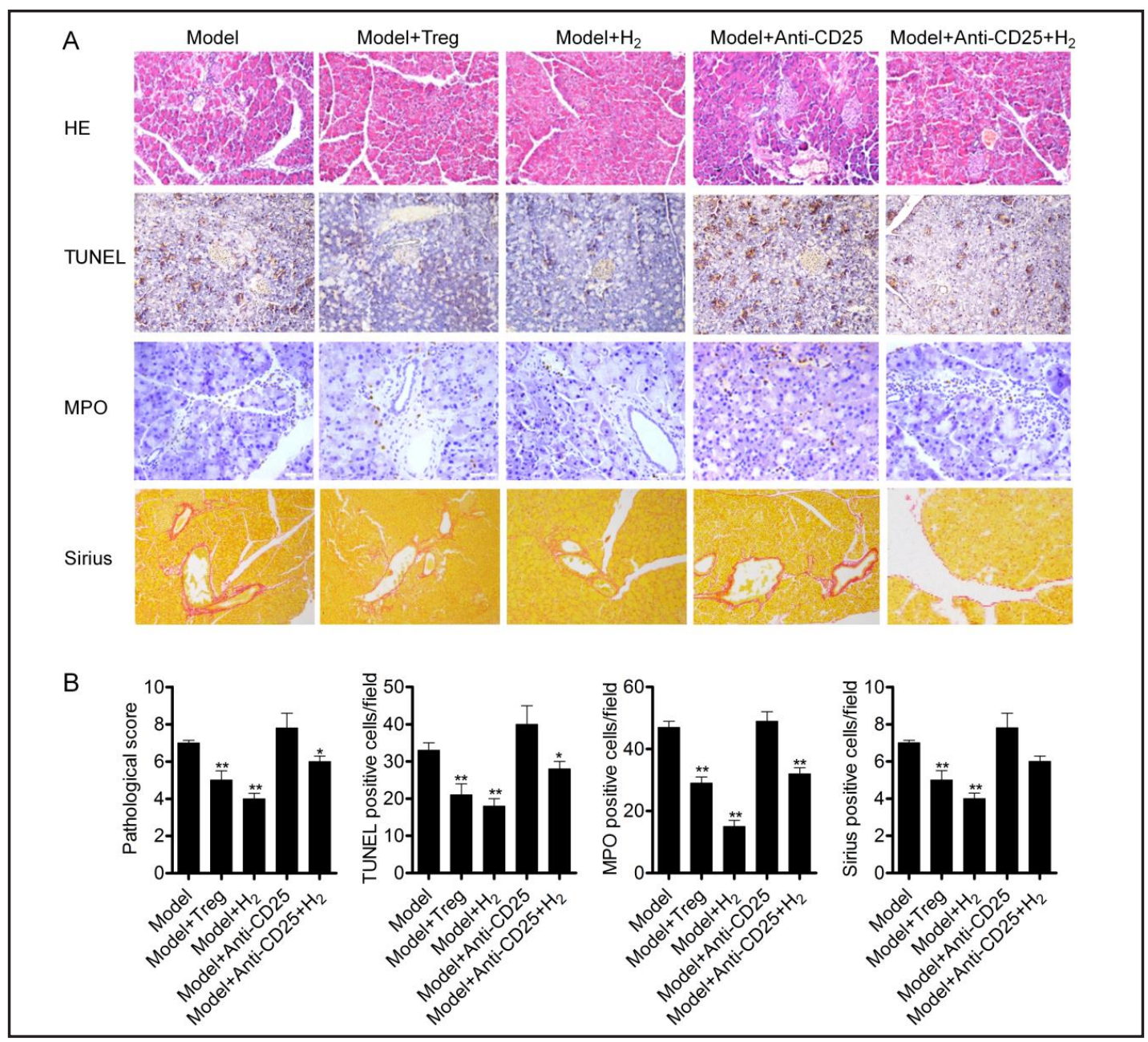

Fig. 6. Adoptive transfer of Treg cells protected chronic pancreatitis mice in histopathology. Tissue inflammation and global cell metaplasia analyzed on HE (magnification $\times 200$ ), TUNEL, MPO (magnification $\times 400$ ), and Sirius staining (magnification $\times 100$ ). ${ }^{*} \mathrm{P}<0.05$ and ${ }^{* *} \mathrm{P}<0.01$ compared with model group.

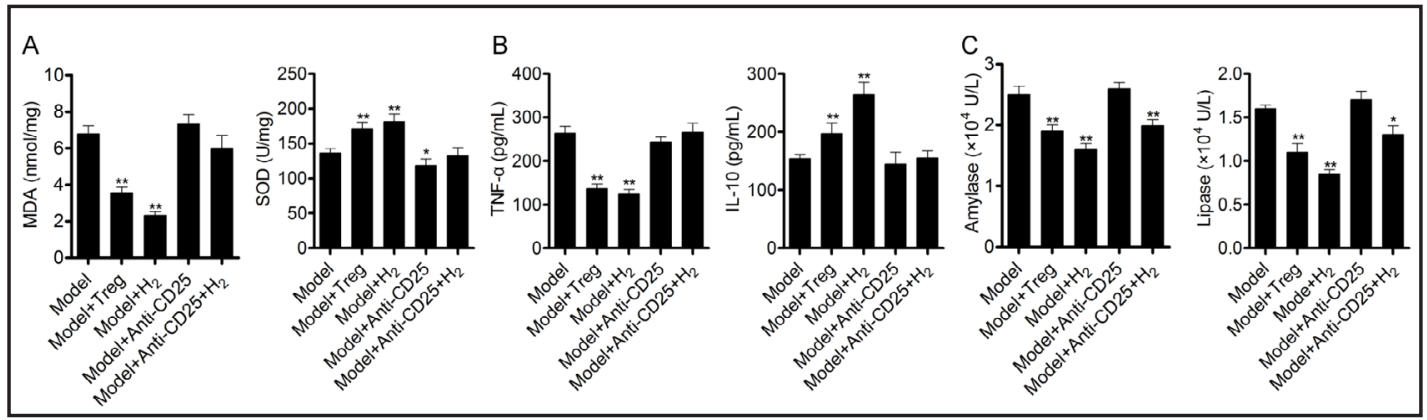

Fig. 7. Adoptive transfer of Treg cells ameliorated oxidative stress, inflammatory cytokines, and the levels of amylase and lipase in chronic pancreatitis mice. Pancreas levels of MDA content, SOD activity (A), TNF- $\alpha$, IL10 (B) cytokine expression and amylase and lipase activity (C) were determined by ELISA and absorbance assay. ${ }^{* *} \mathrm{P}<0.01$ compared with model group.

effect of hydrogen treatment. We also showed that in vitro exposure to Hydrogen-Rich saline prevented $\mathrm{H}_{2} \mathrm{O}_{2}$ induced Treg apoptosis by inhibiting ROS generation.

\section{KARGER}




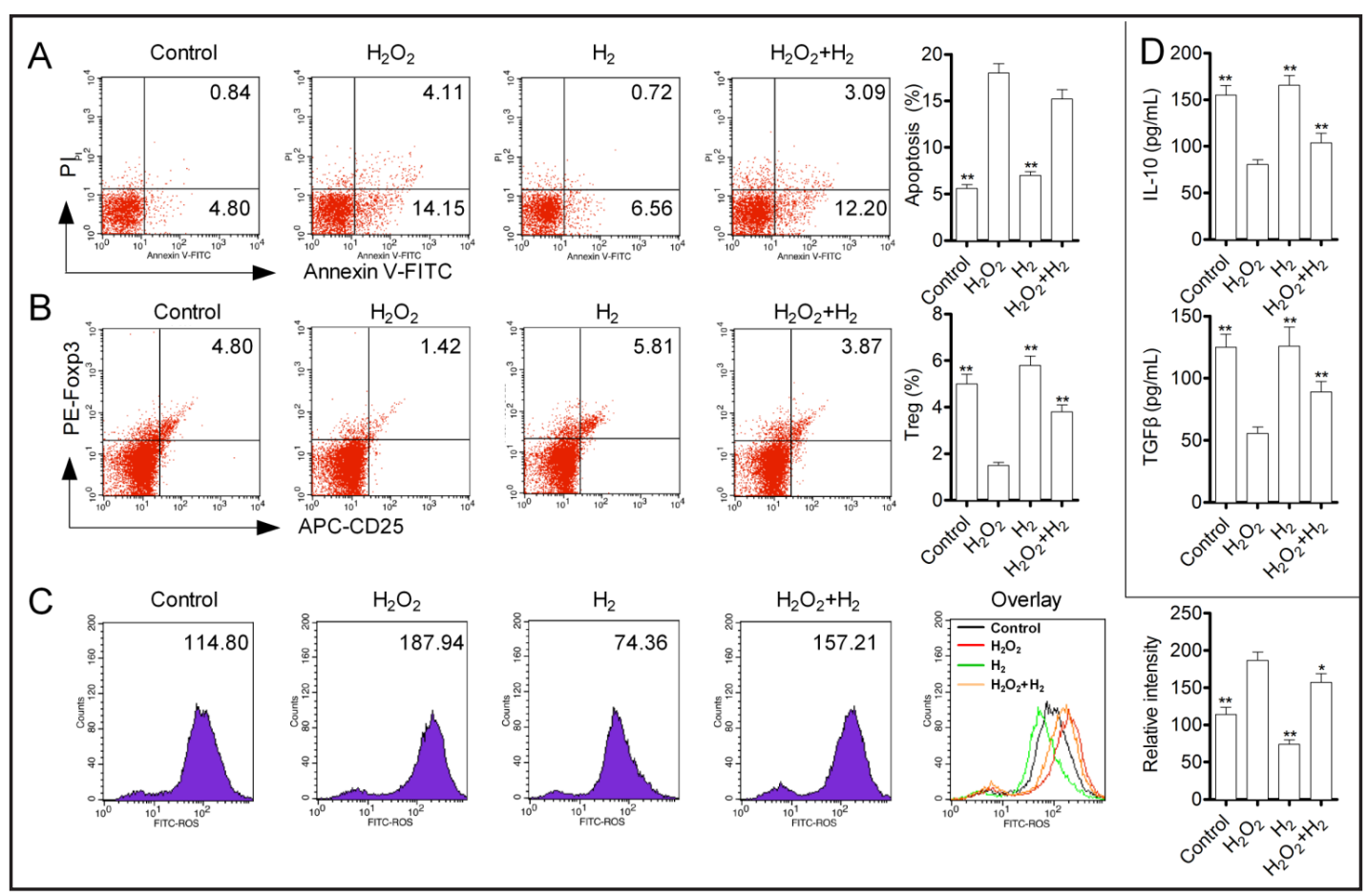

Fig. 8. Hydrogen-Rich saline inhibited $\mathrm{H}_{2} \mathrm{O}_{2}$ induced Treg apoptosis, quantity and ROS level. Treg apoptosis (A), quantity (B) and intracellular level of ROS (C) were analyzed by flow cytometry. The expression of IL-10 and TGF $\beta$ (D) were determined by ELISA. ${ }^{*} \mathrm{P}<0.05$ and ${ }^{* *} \mathrm{P}<0.01$ compared with $\mathrm{H}_{2} \mathrm{O}_{2}$ group.

Chronic pancreatitis is characterized by immune cell infiltration and replacement of the destroyed acinar cells by fibrotic cells. Therefore, dysregulation of immune cells, such as monocytes/macrophages, mast cells and T cells was critical in the pathogenesis of chronic pancreatitis [7]. Among these immune cells, T cells, which were significantly increased in the chronic pancreatitis lesions, were believed to play very important role in killing acinar cells [9]. Tregs functioned as a critical immune cells to maintain tolerance and prevent autoimmune diseases [22]. Multiple mechanisms have been described for how Tregs regulated immune response [23], among them, production of anti-inflammatory cytokine IL-10 was essential in suppressing $T$ cell over activation [24]. In chronic autoimmune pancreatitis patients, the number of Tregs was associated with concentrations of IL-10 in pancreatic tissue lesion [25]. A more recent report confirmed that Tregs could specifically suppress cytotoxic $\mathrm{T}$ cell response [10], which was very important in pancreas tissue destruction of chronic pancreatitis patients [9]. The suppressive effects of Tregs on cytotoxic $\mathrm{T}$ cells were IL-10 dependent $[10,26]$. Similarly, in our study, we found that decreased Tregs in chronic pancreatitis mice (Figs. 4C and D). In contrast, adoptive transfer of Tregs attenuated the severity of chronic pancreatitis, which further supported the protective role of Tregs in chronic pancreatitis (Figs. 5C and D). Moreover, the treatment of hydrogen restored Treg number loss and increased IL-10 levels (Figs. 5C and D, Fig. 7B), which was believed to suppress the over activation of cytotoxic $\mathrm{T}$ cells and reduce the severity of chronic pancreatitis. As the report from Miyoshi et.al, naive Tregs significantly decreased in peripheral blood from patients with autoimmune pancreatitis, although CD4+CD25high Tregs were significantly increased [27]. The finding means increased memory Tregs in the periphery and local tissues may be inhibitory immune response against inflammation in the patients with autoimmune pancreatitis. In animal studies, circulating Tregs decreased after L-arginine injection, and it might be a performance at the early stage of disease. And animal models might be different to patients. 


\section{Cellular Physiology Cell Physiol Biochem 2017;44:2005-2016 \begin{tabular}{l|l|l} 
and Biochemistry $10.1159 / 000485906$ & $\begin{array}{l}\text { D 2 2017 The Author(s). Published by S. Karger AG, Basel } \\
\text { www.karger.com/cpb }\end{array}$ \\
\hline
\end{tabular}

Molecular hydrogen is a strong scavenger of the hydroxyl radical. Hydrogen was reported to selectively reduce the hydroxyl radical, the most cytotoxic of reactive oxygen species (ROS), and effectively protected cells [28]. The therapeutic potential of hydrogen was tested as early as 1970s [29]. More than 30 years later, an important study confirmed the beneficial effects of hydrogen on brain injury by reducing cytotoxic ROS and protecting tissue from oxidative damage [28]. Hydrogen treatments, including inhalation of hydrogen gas and Hydrogen-Rich saline administration, have been tested in many animal models and clinical trials [11, 30, 31]. In general, hydrogen has been described effective in treating a variety range of diseases such as post-cardiac syndrome, Parkinson's disease, acute cerebral ischemia, metabolic syndrome, rheumatoid arthritis, hemodylisis and postpsoriasis [11, $31,32]$. For pancreas disease, previous studies suggested hydrogen was protective in experimental acute pancreatitis by ameliorating oxidative stress [17, 33]. Consistently, in chronic pancreatitis model, we observed reduced oxidative stress and pancreas damage, more importantly, reduced pancreas fibrosis was observed with hydrogen treatment. We also showed the hydrogen can also regulate immune response by promoting Treg survival (Figs. 8A and B). In addition, our study provided novel mechanisms to explain the antiinflammatory effects of hydrogen in several previous reports [34-36].

\section{Conclusion}

We found hydrogen treatment effective attenuated the acinar cell death and improved pancreas fibrosis in L-arginine induced chronic pancreatitis in mice. Hydrogen treatment restored Treg loss in chronic pancreatitis mice and ablation of Tregs abolished the protective effect of hydrogen. Hydrogen promoted the survival of Tregs by blocking ROS production. Therefore, hydrogen can be considered as a very attractive therapeutic method for chronic pancreatitis patients.

\section{Acknowledgements}

This work was supported by the national key clinical specialist construction program of China (Grant Number N/A).

\section{Disclosure Statement}

The authors declare no potential conflicts of interest.

\section{References}

1 Etemad B, Whitcomb DC: Chronic pancreatitis: diagnosis, classification, and new genetic developments. Gastroenterology 2001;120:682-707.

2 Braganza JM, Lee SH, McCloy RF, McMahon MJ: Chronic pancreatitis. Lancet 2011;377:1184-1197.

-3 Habtezion A: Inflammation in acute and chronic pancreatitis. Curr Opin Gastroenterol 2015;31:395-399.

-4 Zheng L, Xue J, Jaffee EM, Habtezion A: Role of immune cells and immune-based therapies in pancreatitis and pancreatic ductal adenocarcinoma. Gastroenterology 2013;144:1230-1240.

5 Chen Y, Zhang J, Zhao Q, Chen Q, Sun Y, Jin Y, Wu J: Melatonin Induces Anti-Inflammatory Effects to Play a Protective Role via Endoplasmic Reticulum Stress in Acute Pancreatitis. Cell Physiol Biochem 2016;40:1094-1104.

6 Chen G, Xu F, Li J, Lu S: Depletion of neutrophils protects against L-arginine-induced acute pancreatitis in mice. Cell Physiol Biochem 2015;35:2111-2120. 


\section{Cellular Physiology Cell Physiol Biochem 2017;44:2005-2016 \begin{tabular}{l|l|l} 
DOI: 10.1159/000485906 & $\begin{array}{l}\text { (c) } 2017 \text { The Author(s). Published by S. Karger AG, Basel } \\
\text { www.karger.com/cpb }\end{array}$
\end{tabular}}

7 Xue J, Sharma V, Habtezion A: Immune cells and immune-based therapy in pancreatitis. Immunol Res 2014;58:378-386.

-8 Demols A, Le Moine 0, Desalle F, Quertinmont E, Van Laethem JL, Deviere J: CD4(+)T cells play an important role in acute experimental pancreatitis in mice. Gastroenterology 2000;118:582-590.

-9 Hunger RE, Mueller C, Z'Graggen K, Friess H, Buchler MW: Cytotoxic cells are activated in cellular infiltrates of alcoholic chronic pancreatitis. Gastroenterology 1997;112:1656-1663.

-10 Schmitz-Winnenthal H, Pietsch DH, Schimmack S, Bonertz A, Udonta F, Ge Y, Galindo L, Specht S, Volk C, Zgraggen K, Koch M, Buchler MW, Weitz J, Beckhove P: Chronic pancreatitis is associated with diseasespecific regulatory T-cell responses. Gastroenterology 2010;138:1178-1188.

$\checkmark 11$ Huang L: Molecular hydrogen: a therapeutic antioxidant and beyond. Med Gas Res 2016;6:219-222.

12 Zheng Y, Zhu D: Molecular Hydrogen Therapy Ameliorates Organ Damage Induced by Sepsis. Oxid Med Cell Longev 2016;2016:5806057.

13 Meng G, Ma Y, Xie L, Albert F, Ji Y: Emerging role of hydrogen sulfide in hypertension and related cardiovascular diseases. Br J Pharmacol 2014;172:5501-5511.

14 Zhang Y, Sun Q He B, Xiao J, Wang Z, Sun X: Anti-inflammatory effect of hydrogen-rich saline in a rat model of regional myocardial ischemia and reperfusion. Int J Cardiol 2011;148:91-95.

15 Kajiyama S, Hasegawa G, Mai A, Hosoda H, Fukui M, Nakamura N, Kitawaki J, Imai S, Nakano K, Ohta M: Supplementation of hydrogen-rich water improves lipid and glucose metabolism in patients with type 2 diabetes or impaired glucose tolerance. Nutr Res 2008;28:137-143.

16 Wang C, Li J, Liu Q, Yang R, Zhang JH, Cao YP, Sun XJ: Hydrogen-rich saline reduces oxidative stress and inflammation by inhibit of JNK and NF- $\mathrm{B}$ activation in a rat model of amyloid-beta-induced Alzheimer's disease. Neurosci Lett 2011;491:127-132.

-17 Zhou HX, Han B, Hou LM, An TT, Jia G, Cheng ZX, Ma Y, Zhou YN, Kong R, Wang SJ, Wang YW, Sun XJ, Pan SH, Sun B: Protective Effects of Hydrogen Gas on Experimental Acute Pancreatitis. PLoS One 2016;11:e0154483.

18 Chen B, Yue R, Yang Y, Zeng H, Chang W, Gao N, Yuan X, Zhang W, Shan L: Protective Effects of (E)-2-(1Hydroxyl-4-Oxocyclohexyl) Ethyl Caffeine Against Hydrogen Peroxide-Induced Injury in PC12 Cells. Neurochem Res 2015;40:531-541.

19 Li Q, Pan Y, Zeng Q Luo B, Cai S, Hui K, Gao Y, Zhu C, Chen X, Duan M: Neuroprotective Effect of HydrogenRich Saline in Global Cerebral Ischemia/Reperfusion Rats: Up-Regulated Tregs and Down-Regulated miR21, miR-210 and NF-кB Expression. Neurochem Res 2016;41:2655-2665.

20 Li N, Wu X, Holzer RG, Lee JH, Todoric J, Park EJ, Ogata H, Gukovskaya AS, Gukovsky I, Pizzo DP, VandenBerg S, Tarin D, Atay C, Arkan MC, Deerinck TJ, Moscat J, Diaz-Meco M, Dawson D, Erkan M, Kleeff J, Karin M: Loss of acinar cell IKKalpha triggers spontaneous pancreatitis in mice. J Clin Invest 2013;123:2231-2243.

21 Bhatia M, Neoptolemos JP, Slavin J: Inflammatory mediators as therapeutic targets in acute pancreatitis. Curr Opin Investig Drugs 2001;2:496-501.

22 Sakaguchi S, Ono M, Setoguchi R, Yagi H, Hori S, Fehervari Z, Shimizu J, Takahashi T, Nomura T: Foxp3+ CD25+ CD4+ natural regulatory T cells in dominant self-tolerance and autoimmune disease. Immunol Rev 2006;212:8-27.

23 Josefowicz SZ, Lu LF, Rudensky AY: Regulatory T cells: mechanisms of differentiation and function. Annu Rev Immunol 2012;30:531-564.

-24 Chaudhry A, Samstein RM, Treuting P, Liang Y, Pils MC, Heinrich JM, Jack RS, Wunderlich FT, Bruning JC, Muller W, Rudensky AY: Interleukin-10 signaling in regulatory T cells is required for suppression of Th17 cell-mediated inflammation. Immunity 2011;34:566-578.

25 Okazaki K, Uchida K, Ohana M, Nakase H, Uose S, Inai M, Matsushima Y, Katamura K, Ohmori K, Chiba T: Autoimmune-related pancreatitis is associated with autoantibodies and a Th1/Th2-type cellular immune response. Gastroenterology 2000;118:573-581.

26 Zheng YS, Wu ZS, Zhang LY, Ke L, Li WQ Li N, Li JS: Nicotine ameliorates experimental severe acute pancreatitis via enhancing immunoregulation of CD4+ CD25+ regulatory T cells. Pancreas 2015;44:500506.

27 Miyoshi H, Uchida K, Taniguchi T, Yazumi S, Matsushita M, Takaoka M, Okazaki K: Circulating naive and CD4+CD25 high regulatory T cells in patients with autoimmune pancreatitis. Pancreas 2008;36:133-140. 


\section{Cellular Physiology Cell Physiol Biochem 2017;44:2005-2016 \begin{tabular}{l|l|l} 
DOI: 10.1159/000485906 & $\begin{array}{l}\text { O 2017 The Author(s). Published by S. Karger AG, Basel } \\
\text { www.karger.com/cpb }\end{array}$ \\
\hline
\end{tabular}

-28 Ohsawa I, Ishikawa M, Takahashi K, Watanabe M, Nishimaki K, Yamagata K, Katsura K, Katayama Y, Asoh S, Ohta S: Hydrogen acts as a therapeutic antioxidant by selectively reducing cytotoxic oxygen radicals. Nat Med 2007;13:688-694.

29 Dole M, Wilson FR, Fife WP: Hyperbaric hydrogen therapy: a possible treatment for cancer. Science 1975;190:152-154.

-30 Ichihara M, Sobue S, Ito M, Hirayama M, Ohno K: Beneficial biological effects and the underlying mechanisms of molecular hydrogen-comprehensive review of 321 original articles. Med Gas Res 2015;5:12.

-31 Ohta S: Recent progress toward hydrogen medicine: potential of molecular hydrogen for preventive and therapeutic applications. Curr Pharm Des 2011;17:2241-2252.

32 Dixon BJ, Tang J, Zhang JH: The evolution of molecular hydrogen: a noteworthy potential therapy with clinical significance. Med Gas Res 2013;3:1-12.

33 Shi Q Chen C, Deng WH, Wang P, Zuo T, Zhao L, Yu J, Zhao KL, Mei FC, Li C, Wang GR, Wang WX: HydrogenRich Saline Attenuates Acute Hepatic Injury in Acute Necrotizing Pancreatitis by Inhibiting Inflammation and Apoptosis, Involving JNK and p38 Mitogen-Activated Protein Kinase-dependent Reactive Oxygen Species. Pancreas 2016;45:1424-1431.

34 Gharib B, Hanna S, Abdallahi OM, Lepidi H, Gardette B, De Reggi M: Anti-inflammatory properties of molecular hydrogen: investigation on parasite-induced liver inflammation. C R Acad Sci III 2001;324:719724.

-35 Liu L, Xie K, Chen H, Dong X, Li Y, Yu Y, Wang G: Inhalation of hydrogen gas attenuates brain injury in mice with cecal ligation and puncture via inhibiting neuroinflammation, oxidative stress and neuronal apoptosis. Brain Res 2014;1589:78-92.

36 Zhang J, Wu Q, Song S, Wan Y, Zhang R, Tai M, Liu C: Effect of hydrogen-rich water on acute peritonitis of rat models. Int Immunopharmacol 2014;21:94-101. 